\title{
Histopathological evaluation of polycaprolactone nanocomposite compared with tricalcium phosphate in bone healing
}

\author{
Hadi Eftekhari ${ }^{1}$, Alireza Jahandideh ${ }^{1}$, Ahmad Asghari ${ }^{1}$, \\ Abolfazl Akbarzadeh ${ }^{2,4}$, Saeed Hesaraki ${ }^{3}$ \\ ${ }^{1}$ Department of Clinical Science, ${ }^{3}$ Department of Pathobiology, \\ Faculty of Specialized Veterinary Sciences, Science and Research Branch, \\ Islamic Azad University, 1477893855 Tehran, Iran \\ ${ }^{2}$ Universal Scientific Education and Research Network (USERN), 5165665811 Tabriz, Iran \\ ${ }^{4}$ Drug Applied Research Center, Tabriz University of Medical Sciences, 5165665811 Tabriz, Iran \\ dr.jahandideh@gmail.com
}

Received: February 1,2018 Accepted: September 26, 2018

\begin{abstract}
Introduction: In recent years, the use of bone scaffolds as bone tissue substitutes, especially the use of such as hydroxyapatite and tricalcium phosphate, has been very popular. Today, the use of modern engineering techniques and advances in nanotechnology have expanded the use of nanomaterials as bone scaffolds for bone tissue applications. Material and Methods: This study was performed on 60 adult male New Zealand rabbits divided into four experimental groups: the control group without any treatment, the second group receiving hydroxyapatite, the third group treated with $\beta$-tricalcium phosphate, and the fourth group receiving nanocomposite polycaprolactone (PCL) scaffold. In a surgical procedure, a defect 6 mm in diameter was made in a hind limb femur. Four indexes were used to assess histopathology, which were union index, spongiosa index, cortex index, and bone marrow. Results: The results showed that nanocomposite PCL and control groups always had the respective highest and lowest values among all the groups at all time intervals. The histopathological assessment demonstrated that the quantity of newly formed lamellar bone in the nanocomposite PCL group was higher than in other groups. Conclusion: All these data suggest that PCL had positive effects on the bone healing process, which could have great potential in tissue engineering and clinical applications.
\end{abstract}

Keywords: rabbits, bone healing, nanocomposite polycaprolactone, $\beta$-tricalcium phosphate, hydroxyapatite.

\section{Introduction}

Bone defects are caused by trauma, injury, cancer, infection, and some other factors. Their repair is a major challenge in orthopaedic surgery. There have been and continue to be numerous efforts to find materials or medications for the improvement of bone repair (5). Among the various methods available for this purpose, bone autograft has been considered the gold standard because of its osteoinductive and osteoconductive properties, high biocompatibility, and lesser risk of transmission of pathogens. Although autografts have shown the best clinical results, the need to perform a separate operation to harvest bone tissue needed for transplantation can in some cases lead to problems such as nerve injury, difficulty in walking, numbness, and back pain. The application of tissue engineering makes it possible to safely repair bone defects without the need for other surgical procedures using bone replacement. Up to now, a variety of natural or synthetic materials such as metals, ceramics, and polymers have been used to stimulate and enhance the process of bone regeneration. Ceramics are widely employed in tissue engineering, especially in bone regeneration (8). They can have either natural origins such as hydroxyapatite (HA), or synthetic origins, such as synthetic hydroxyapatite or $\beta$-tricalcium phosphate. Calcium phosphate ceramics have excellent biocompatibility and biodegradability, can be properly attached to bone tissue, and facilitate the healing process. In comparison with others, tricalcium phosphate (TCP) ceramics effect better 
osteoconduction and are highly biodegradable, as well as rapidly replaceable by bone matrix due to good absorption. (6). In recent years, the use of modern technology and especially nanotechnology in tissue engineering and the production of bone scaffolds has led to major improvements in the production of nanobased bony scaffolds. The nanofibres can be constructed with different pore architectures that have a high surface to volume ratio. Polycaprolactone (PCL) is one of the synthetic polymers which are extensively used in scaffold development and application in orthopaedics. The biocompatibility, bioabsorbability, and mechanical strength of PCL make it a good choice to study in tissue engineering (25). This highly biocompatible polymer is degraded to innocuous byproducts which are metabolised via the tricarboxylic acid cycle. The aim of this study was to evaluate nanocomposite PCL in comparison with TCP in bone healing.

\section{Material and Methods}

This investigation was approved by the Committee of Ethics in Research with animals at the Islamic Azad University. The study was designed to minimise the number of animals required for the experiments.

Synthesis of calcium phosphate powders. The synthesis of calcium phosphate $(\mathrm{CaP})$ powders was carried out by the sol-gel method. First, certain quantities of phosphoric pentoxide $\left(\mathrm{P}_{2} \mathrm{O}_{5}\right)$ and calcium nitrate tetrohydrate $\mathrm{Ca}\left(\mathrm{NO}_{3}\right)_{2} \cdot 4 \mathrm{H}_{2} \mathrm{O}$ were dissolved in absolute ethyl alcohol with a $\mathrm{pH}$ of 10.5 to form $0.5 \mathrm{~mol} / \mathrm{L}$ and $1.67 \mathrm{~mol} / \mathrm{L}$ solutions, respectively. After this, these solutions were mixed together to obtain $\mathrm{Ca} / \mathrm{P}$ molar ratios of 1.5 (TCP) and 1.67 (HA). The resultant mixture was stirred for $30 \mathrm{~min}$ and then was heated in a water bath at $60^{\circ} \mathrm{C}$ for $1 \mathrm{~h}$. The obtained gel was subsequently dried at $80^{\circ} \mathrm{C}$ for $24 \mathrm{~h}$ in an air oven and calcined at $700^{\circ} \mathrm{C}$ for $3 \mathrm{~h}$ in a furnace. After that, the products were sintered at $1,200^{\circ} \mathrm{C}$ for $2 \mathrm{~h}$ and then were exposed to a cooling system to reach ambient temperature. Subsequently, the sintered products were crushed using an agate mortar to obtain granules.

Characterisation of synthesised powder. The specific surface area was calculated by 15 -point BET measurement (Micromeritics Gemini 2360, USA). X-ray diffraction (XRD) patterns were obtained using a Philips PW 1371 diffractometer (the Netherlands) and $\mathrm{Cu} \mathrm{K \alpha}$ radiation. Infrared spectra of the samples were recorded on a Brucker IFS 48 FTIR spectrometer (USA) and the analysis was performed in the range of 400 to $4,000 \mathrm{~cm}^{-1}$ with a resolution of $5 \mathrm{~cm}^{-1}$ using $\mathrm{KBr}$ pellets. the samples were analysed by a Cambridge Instruments Stereoscan 360 scanning electron microscope (SEM) (UK).

Experimental animals. A total of 60 adult male New Zealand rabbits were used in the study, aged six to eight months and weighing 3-3.5 kg. They were kept according to the norms of the laboratory of animal experimentation in the Islamic Azad University Faculty of Specialized Veterinary Sciences. To decrease the genetic differences, all animals were obtained from a common source. The rabbits were housed in individual cages during the entire study period, fed standard pellets, and given fresh water. They were kept under standard environmental conditions at humidity of $60 \pm 5 \%$, temperature of $18 \pm 3^{\circ} \mathrm{C}$ in a $12 \mathrm{~h}$ light-dark cycle. The animals were divided into four equal groups.

Surgical procedures. Animals were anaesthetised by intramuscular injection of $10 \%$ ketamine hydrochloride, $50 \mathrm{mg} / \mathrm{kg}$, (Alfasan, the Netherlands) and 2\% Rompun (xylazine, $5 \mathrm{mg} / \mathrm{kg}$, Alfasan, the Netherlands). Then, the surgery site was clipped of hair and cleaned with soap. Scrubbing of the surgical site by antiseptic agents followed. An incision approximately $5 \mathrm{~cm}$ in length was made in the middle of the right hind limb, then the femur was exposed by blunt dissection of the femoral muscle. The bone periosteum was removed using a periosteal elevator and then a bilateral defect (in diameter of $6 \mathrm{~mm}$ ) was made in the femur using an orthopaedic drill. This defect site was washed out with $0.9 \%$ saline solution and then the periosteum around the osteotomy site was sutured by overlying muscles. Finally, the defect was treated if the animal was in an experimental group.

Treatment. Before concluding the surgery, the rabbits were randomly divided into four equal groups. The defect was left unfilled without the use of any substance in the first group as a control group. In the second group, the bone defect was filled with HA bone scaffold, in the third group, TCP bone scaffold was used, and in the fourth group, the defect was filled with PCL nanocomposite bone scaffold. Finally, the periosteum, muscles, and skin were sutured in the usual way. To prevent infection, an antibiotic (penicillin G procaine $40,000 \mathrm{IU} / \mathrm{kg}$ i.m., Dena, Iran) was used for three days after surgery. Tramadol hydrochloride ( $5 \mathrm{mg} / \mathrm{kg}$, i.m., Exir, Iran) was administered to relieve pain for three postoperative days. To avoid self-injury, the rabbits were kept separately in individual cages.

A daily checkup was made to monitor any sign of infection, inflammation, or dehiscence at the operating site. At 15, 30, and 45 days after surgery, five rabbits from each group were randomly euthanised by intravenous infusion of Euthasol (pentobarbital; $2 \mathrm{~mL} / 4.5 \mathrm{~kg}$, Chemische Fabrik Berg, Germany). Finally, the right hind limb femur of each animal was removed and fixed in $10 \%$ formalin for histological analysis.

Histopathological study. Routinely prepared paraffin sections of $5 \mu \mathrm{m}$ thickness were stained with haematoxylin and eosin $(\mathrm{H} \& \mathrm{E})$ and examined under a light microscope. The features of specimens, including the quality of the union index, appearance and quality of the spongiosa, cortical development, and assessment of the bone marrow, were evaluated using a 16-point histological grading system. 
Statistical analysis. All data were analysed with the statistical software SPSS 22 (SPSS Inc., USA). One-way analysis of variance (ANOVA) was used to calculate the statistical significance. Results were expressed as the mean + standard deviation. The level of significance was considered to be $\mathrm{P}<0.05$ (3).

\section{Results}

Statistical analysis of bone parameters. The statistical analysis showed that the nanocomposite PCL group had the highest union index value $(1.8 \pm 0.83)$ on day 15 , and the control group had the lowest value $(0.2 \pm 0.44)$. On day 30 the highest value was in the nanocomposite PCL group $(3.4 \pm 0.54)$, and the lowest was in the control group $(1 \pm 0.7)$. The nanocomposite PCL and control groups exhibited the respective highest and lowest values among all the groups in union index at any time interval (Table 1). The results of the comparison of the average union indices among the groups indicated that there was a statistically significant difference between them $(\mathrm{P}<0.05)$ (Table 2).
The spongiosa indices of all groups are shown in Table 3. According to these statistics, the highest score on day 15 was for the nanocomposite PCL $(1.4 \pm 0.5)$ group, and the lowest was for the control group $(0.2 \pm$ 0.44). The nanocomposite PCL group had the highest spongiosa index on day $30(3 \pm 1)$, and the control group had the lowest $(0.8 \pm 0.83)$. on day 45 the nanocomposite PCL and control groups also exhibited the respective highest and lowest values (Table 3 ). Comparison of the average spongiosa indices among the groups revealed a statistically significant difference between them $(\mathrm{P}<0.05)$ (Table 4$)$.

As shown in Table 5, the nanocomposite PCL group showed the highest cortex index on day $15(1.8 \pm$ $0.83)$ and the control group showed the lowest $(0.2 \pm$ 0.44). On day 30, the highest value was in the nanocomposite PCL group $(2.8 \pm 0.83)$, and the lowest was in the control group $(1 \pm 0.7)$. on day 45 the nanocomposite PCL and control groups also showed the respective highest and lowest values. Comparison of average cortex indices among the groups indicated that there was a statistically significant difference between them $(\mathrm{P}<0.05)$ (Table 6).

Table 1. Statistical analysis of union index

\begin{tabular}{llll}
\hline \multicolumn{1}{c}{ Day } & 15 & 30 & 45 \\
\hline Group & $0.2 \pm 0.447$ & $1 \pm 0.707$ & $2 \pm 0.707$ \\
\hline Hydroxyapatite & $0.8 \pm 0.836$ & $2 \pm 0.707$ & $2.6 \pm 0.894$ \\
\hline$\beta$-tricalcium phosphate & $1 \pm 0.707$ & $2.6 \pm 1.14$ & $3.4 \pm 0.894$ \\
\hline $\begin{array}{l}\text { Nanocomposite } \\
\text { polycaprolactone }\end{array}$ & $1.8 \pm 0.836$ & $3.4 \pm 0.547$ & $3.8 \pm 0.447$ \\
\hline
\end{tabular}

Table 2. Average union indices

\begin{tabular}{|c|c|c|c|c|c|}
\hline Group & number & Average score & Test statistics & $\mathrm{df}$ & Sig \\
\hline \multirow{3}{*}{ Control } & 5 & 4 & \multirow{3}{*}{9.009} & \multirow{3}{*}{2} & \multirow{3}{*}{0.011} \\
\hline & 5 & 7.9 & & & \\
\hline & 5 & 12.1 & & & \\
\hline \multirow{3}{*}{ Hydroxyapatite } & 5 & 4.1 & \multirow{3}{*}{7.138} & \multirow{3}{*}{2} & \multirow{3}{*}{0.028} \\
\hline & 5 & 8.6 & & & \\
\hline & 5 & 11.3 & & & \\
\hline \multirow{3}{*}{$\begin{array}{l}\beta \text {-tricalcium } \\
\text { phosphate }\end{array}$} & 5 & 3.7 & \multirow{3}{*}{8.258} & \multirow{3}{*}{2} & \multirow{3}{*}{0.016} \\
\hline & 5 & 8.8 & & & \\
\hline & 5 & 11.5 & & & \\
\hline \multirow{3}{*}{$\begin{array}{l}\text { Nanocomposite } \\
\text { polycaprolactone }\end{array}$} & 5 & 3.4 & \multirow{3}{*}{9.508} & \multirow{3}{*}{2} & \multirow{3}{*}{0.009} \\
\hline & 5 & 9.2 & & & \\
\hline & 5 & 11.4 & & & \\
\hline
\end{tabular}


Table 3. Statistical analysis of spongiosa index

\begin{tabular}{llll}
\hline Group & 15 & 30 & 45 \\
\hline Control & $0.2 \pm 0.447$ & $0.8 \pm 0.836$ & $2 \pm 0.707$ \\
\hline Hydroxyapatite & $0.6 \pm 0.547$ & $1.2 \pm 0.447$ & $2.8 \pm 0.836$ \\
\hline$\beta$-tricalcium phosphate & $1 \pm 0.707$ & $2.2 \pm 0.447$ & $3.2 \pm 0.447$ \\
\hline $\begin{array}{l}\text { Nanocomposite } \\
\text { polycaprolactone }\end{array}$ & $1.4 \pm 0.547$ & $3 \pm 1$ & $3.8 \pm 0.447$ \\
\hline
\end{tabular}

Table 4. Average spongiosa indices

\begin{tabular}{|c|c|c|c|c|c|}
\hline Group & number & Average score & Test statistics & df & Sig \\
\hline \multirow{3}{*}{ Control } & 5 & 4.5 & \multirow{3}{*}{8.422} & \multirow{3}{*}{2} & \multirow{3}{*}{0.015} \\
\hline & 5 & 7.3 & & & \\
\hline & 5 & 12.2 & & & \\
\hline \multirow{3}{*}{ Hydroxyapatite } & 5 & 4.2 & \multirow{3}{*}{10.818} & \multirow{3}{*}{2} & \multirow{3}{*}{0.004} \\
\hline & 5 & 7 & & & \\
\hline & 5 & 12.8 & & & \\
\hline \multirow{3}{*}{$\beta$-tricalcium phosphate } & 5 & 3.4 & \multirow{3}{*}{11.482} & \multirow{3}{*}{2} & \multirow{3}{*}{0.003} \\
\hline & 5 & 8 & & & \\
\hline & 5 & 12.6 & & & \\
\hline \multirow{3}{*}{$\begin{array}{l}\text { Nanocomposite } \\
\text { polycaprolactone }\end{array}$} & 5 & 3.4 & \multirow{3}{*}{9.789} & \multirow{3}{*}{2} & \multirow{3}{*}{0.007} \\
\hline & 5 & 8.9 & & & \\
\hline & 5 & 11.7 & & & \\
\hline
\end{tabular}

Table 5. Statistical analysis of cortex index

\begin{tabular}{llll}
\hline \multicolumn{1}{c}{ Day } & 15 & 30 & 45 \\
\hline Control & $0.2 \pm 0.447$ & $1 \pm 0.707$ & $1.8 \pm 0.447$ \\
\hline Hydroxyapatite & $0.6 \pm 0.547$ & $1.4 \pm 0.547$ & $2.2 \pm 0.836$ \\
\hline$\beta$-tricalcium phosphate & $1.4 \pm 0.547$ & $2 \pm 0.707$ & $3.2 \pm 0.836$ \\
\hline $\begin{array}{l}\text { Nanocomposite } \\
\text { polycaprolactone }\end{array}$ & $1.8 \pm 0.836$ & $2.8 \pm 0.836$ & $3.6 \pm 0.547$ \\
\hline
\end{tabular}

Table 6. Average cortex indices

\begin{tabular}{|c|c|c|c|c|c|}
\hline Group & number & Average score & Test statistics & $\mathrm{df}$ & Sig \\
\hline \multirow{3}{*}{ Control } & 5 & 4 & \multirow{3}{*}{8.96} & \multirow{3}{*}{2} & \multirow{3}{*}{0.011} \\
\hline & 5 & 8 & & & \\
\hline & 5 & 12 & & & \\
\hline \multirow{3}{*}{ Hydroxyapatite } & 5 & 5 & \multirow{3}{*}{7.808} & \multirow{3}{*}{2} & \multirow{3}{*}{0.02} \\
\hline & 5 & 6.9 & & & \\
\hline & 5 & 12.1 & & & \\
\hline \multirow{3}{*}{$\beta$-tricalcium phosphate } & 5 & 4.2 & \multirow{3}{*}{8.076} & \multirow{3}{*}{2} & \multirow{3}{*}{0.018} \\
\hline & 5 & 8.2 & & & \\
\hline & 5 & 11.6 & & & \\
\hline \multirow{3}{*}{$\begin{array}{l}\text { Nanocomposite } \\
\text { polycaprolactone }\end{array}$} & 5 & 4.2 & \multirow{3}{*}{7.591} & \multirow{3}{*}{2} & \multirow{3}{*}{0.022} \\
\hline & 5 & 8.1 & & & \\
\hline & 5 & 11.7 & & & \\
\hline
\end{tabular}


Table 7. Statistical analysis of bone marrow index

\begin{tabular}{llll}
\hline \multicolumn{1}{c}{ Day } & 15 & 30 & 45 \\
\hline Group & $0.2 \pm 0.447$ & $1 \pm 0.707$ & $1.4 \pm 0.547$ \\
\hline Hydroxyapatite & $1 \pm 0.707$ & $1.4 \pm 0.547$ & $2.4 \pm 0.547$ \\
\hline$\beta$-tricalcium phosphate & $1.4 \pm 0.547$ & $1.8 \pm 0.836$ & $2.8 \pm 0.447$ \\
\hline $\begin{array}{l}\text { Nanocomposite } \\
\text { polycaprolactone }\end{array}$ & $1.6 \pm 0.547$ & $2.4 \pm 0.547$ & $3.4 \pm 0.547$ \\
\hline
\end{tabular}

Table 8. Average bone marrow indices

\begin{tabular}{|c|c|c|c|c|c|}
\hline Groups & number & Average scores & Test statistics & df & Sig \\
\hline \multirow{3}{*}{ Control } & 5 & 4.20 & \multirow{3}{*}{7.023} & \multirow{3}{*}{2} & \multirow{3}{*}{0.030} \\
\hline & 5 & 8.80 & & & \\
\hline & 5 & 11 & & & \\
\hline \multirow{3}{*}{ Hydroxyapatite } & 5 & 5 & \multirow{3}{*}{7.736} & \multirow{3}{*}{2} & \multirow{3}{*}{0.021} \\
\hline & 5 & 6.90 & & & \\
\hline & 5 & 12.10 & & & \\
\hline \multirow{3}{*}{$\beta$-tricalcium phosphate } & 5 & 5 & \multirow{3}{*}{7.280} & \multirow{3}{*}{2} & \multirow{3}{*}{0.26} \\
\hline & 5 & 7 & & & \\
\hline & 5 & 12 & & & \\
\hline \multirow{3}{*}{$\begin{array}{l}\text { Nanocomposite } \\
\text { polycaprolactone }\end{array}$} & 5 & 3.90 & \multirow{3}{*}{10.092} & \multirow{3}{*}{2} & \multirow{3}{*}{0.006} \\
\hline & 5 & 7.70 & & & \\
\hline & 5 & 12.40 & & & \\
\hline
\end{tabular}

As shown in table 7, the bone marrow index in the nanocomposite PCL group on day 15 was $1.6 \pm 0.54$ and the highest, while the control group had the lowest index of $0.2 \pm 0.44$. On day 30 as well the highest value was that of nanocomposite PCL group with an index of $2.4 \pm 0.54$, and the lowest was the control group with an index of $1 \pm 0.7$. on day 45 the nanocomposite PCL and control groups exhibited the respective highest and lowest values (Table 7). According to a comparison of average bone marrow indices, there was a statistically significant difference between them $(\mathrm{p}<0.05)$ except for (not exclusively) the $\beta$-tricalcium phosphate group (Table 8).

Histopathological assessment results. The results of the histopathological assessment are shown in Figs 1-12. According to this assessment, the healing area in the control group on the $15^{\text {th }}$ day of healing showed abundant capillary buds in granulation tissue (Fig. 1). Fibrous tissue along with haemorrhages was seen in the healing area of the HA group on the $15^{\text {th }}$ day of healing (Fig. 2). The healing area of the $\beta$-tricalcium phosphate group showed abundant calcified cartilage (Fig. 3). The healing area in the nanocomposite PCL group exhibited formation of primary bone and granulation tissue that made an imperfect organic bone matrix with haemorrhages (Fig. 4). On the $30^{\text {th }}$ day of healing, the healing area in the control group revealed abundant fibrous tissue filling the marrow space (Fig. 5). Calcified cartilage in the mature granulation tissue was seen in the healing area in the HA group (Fig. 6). The healing area in the $\beta$-tricalcium phosphate group showed the production of primary bone (Fig. 7). The healing area in the nanocomposite PCL group also showed also that woven bones were being produced (Fig. 8). On the $45^{\text {th }}$ day of the healing process, the control group exhibited bone deposition within cartilage in the healing site that indicated primary ossification (Fig. 9). At this time, the healing area of the HA group showed that the defect is filled with primary bone and well-formed marrow (Fig. 10). Lamellar bone formation was seen in the healing area of the $\beta$-tricalcium phosphate group (Fig. 11). The healing area of the nanocomposite PCL group indicated that the defect was filled with lamellar bone (Fig. 12). Furthermore, it showed evidence of an advanced remodelling phase and consolidation developing the Haversian system in the repaired construct. In addition, the amount of newly formed lamellar bone at healing site was more than that of other groups. 


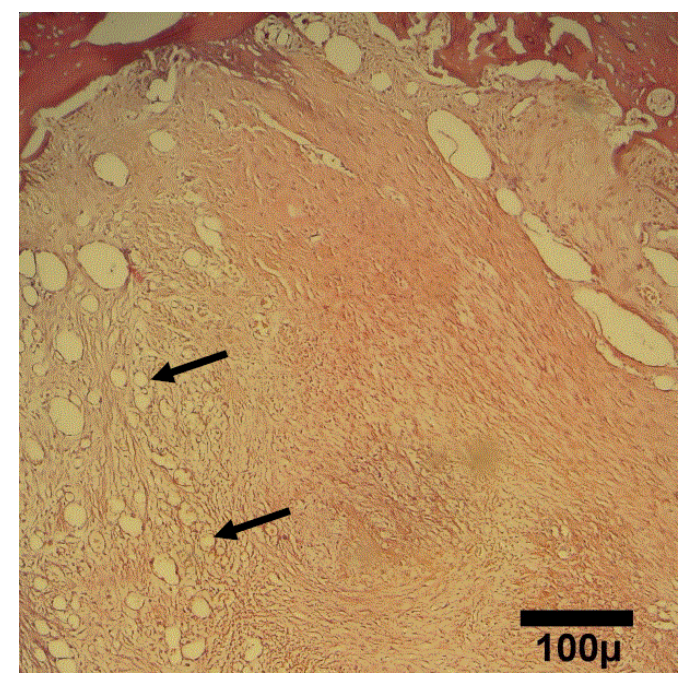

Fig. 1. Microscopic view of healing area in control group on day 15. It shows abundant capillary buds (arrows) in granulation tissue $(\mathrm{H} \& \mathrm{E}, 100 \times)$

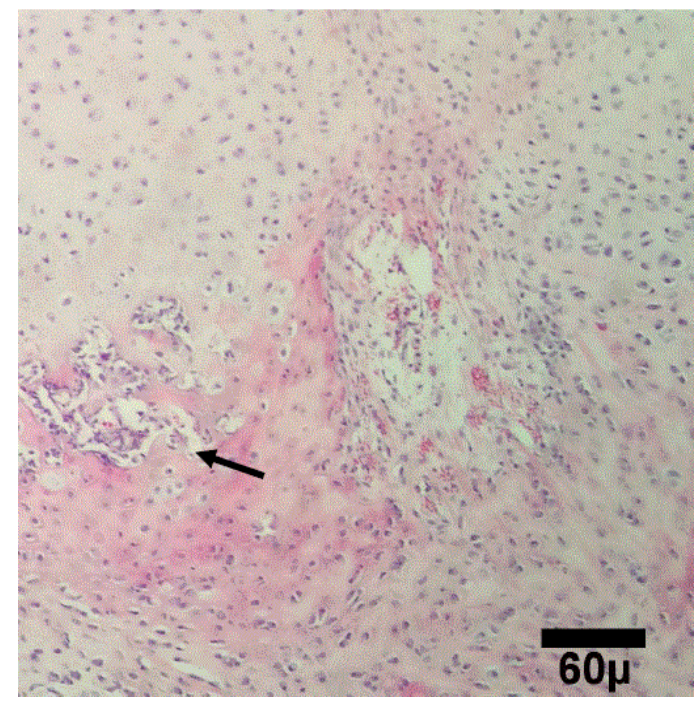

Fig. 2. Microscopic view of healing area in tricalcium phosphate (TCP) group on day 15 . It shows abundant calcified cartilage (arrow) (H\&E, 100×)

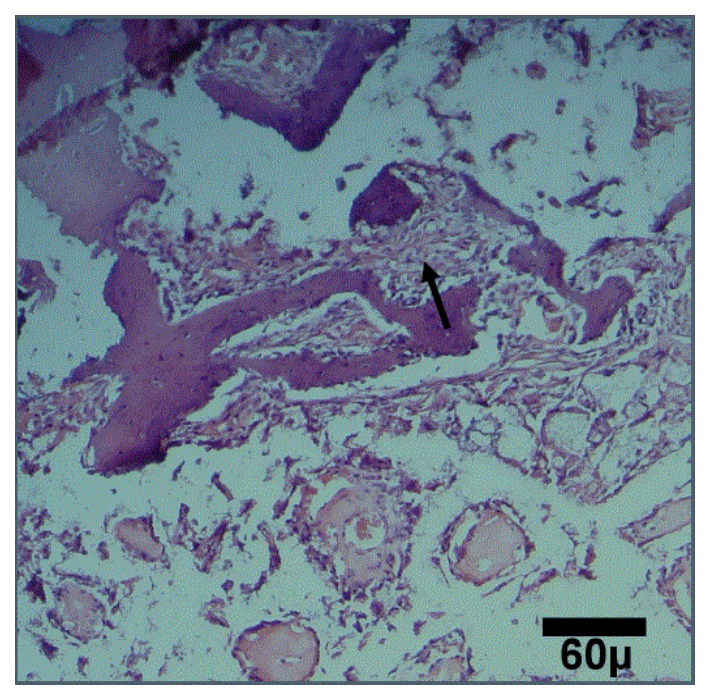

Fig. 3. Microscopic view of healing area in hydroxyapatite (HA) group on day 15.It shows fibrous tissue (arrow) (H\&E, $100 \times)$

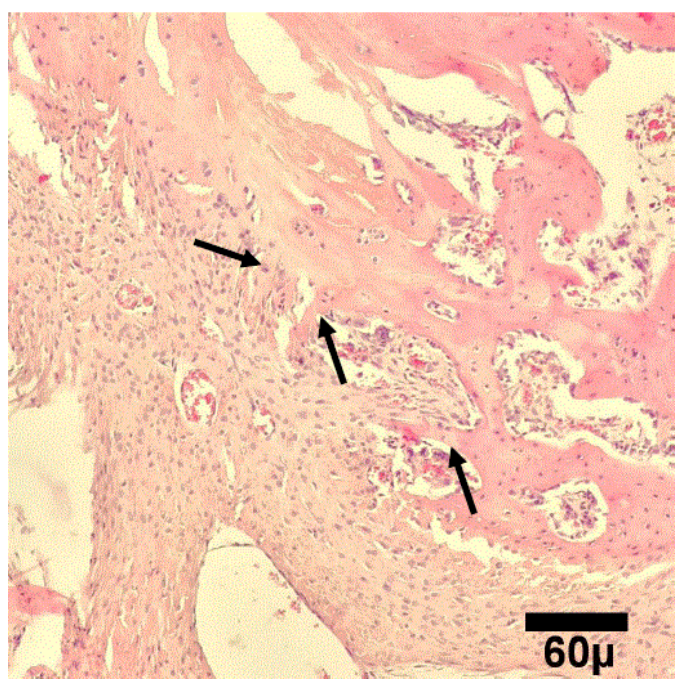

Fig. 4. Microscopic view of healing area in PCL group on day 15 . It shows primary bone (arrows) formation (H\&E, $100 \times)$

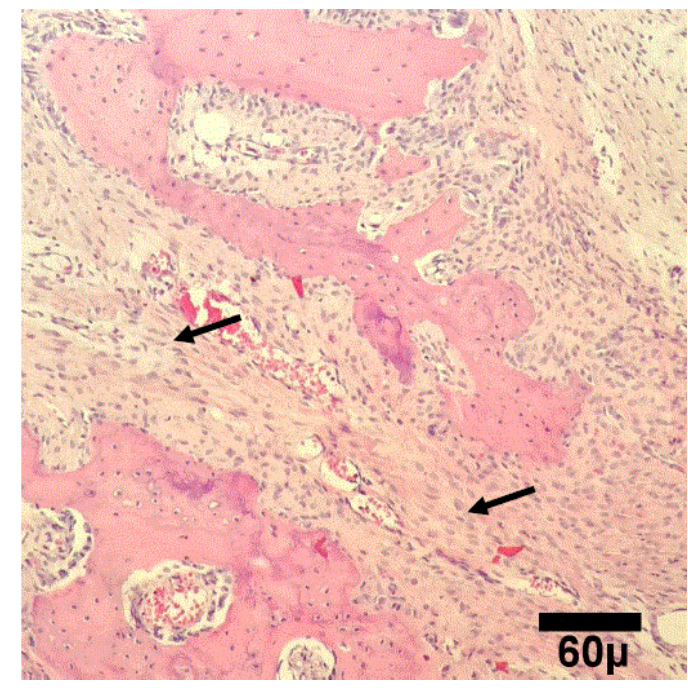

Fig. 5. Microscopic view of healing area in control group on day 30. It shows abundant fibrous tissue (arrows) filling marrow space $(\mathrm{H} \& \mathrm{E}, 100 \times)$

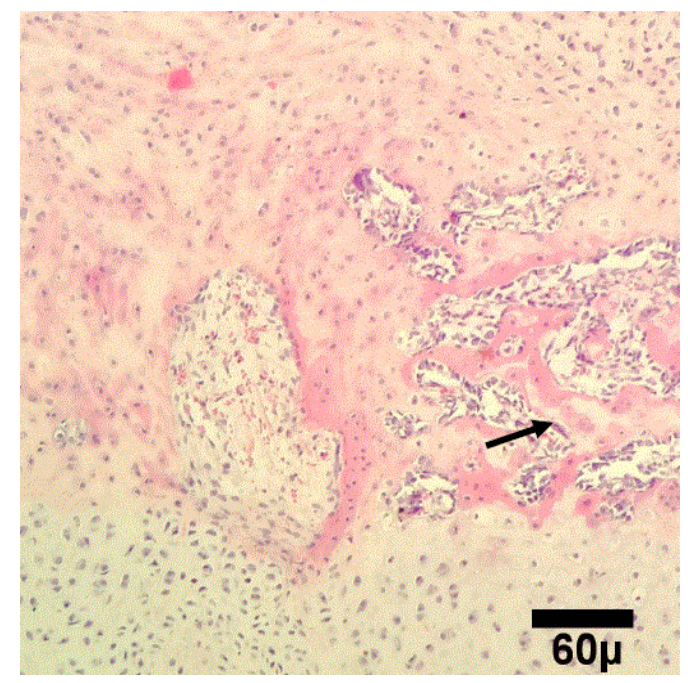

Fig. 6. Microscopic view of healing area in tricalcium phosphate (TCP) group on day 30. Primary bones (arrow) are being produced $(\mathrm{H} \& \mathrm{E}, 100 \times)$ 


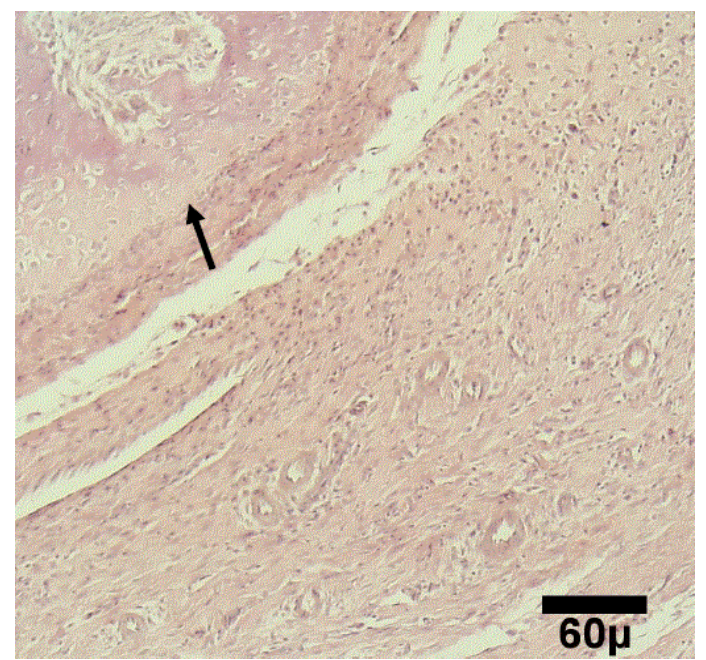

Fig. 7. Microscopic view of healing area in hydroxyapatite group on day 30 . Calcified cartilage (arrow) in the mature granulation tissue $(\mathrm{H} \& \mathrm{E}, 100 \times)$

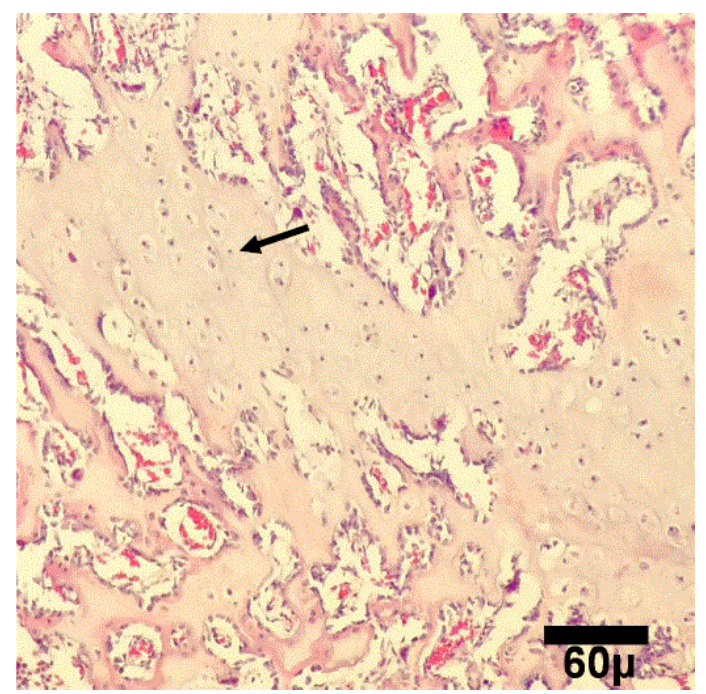

Fig. 8. Microscopic view of healing area in PCL group on day 30 . Woven bones (arrows) are being produced (H\&E, $100 \times)$

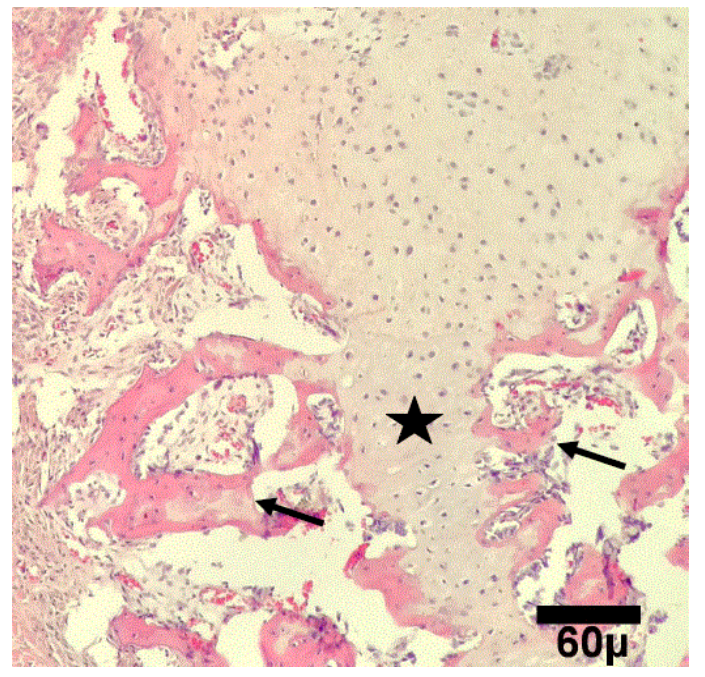

Fig. 9. Microscopic view of healing area in control group on day 45 . Bone deposition within cartilage (star) at healing site shows primary (arrows) ossification (H\&E, 100×)

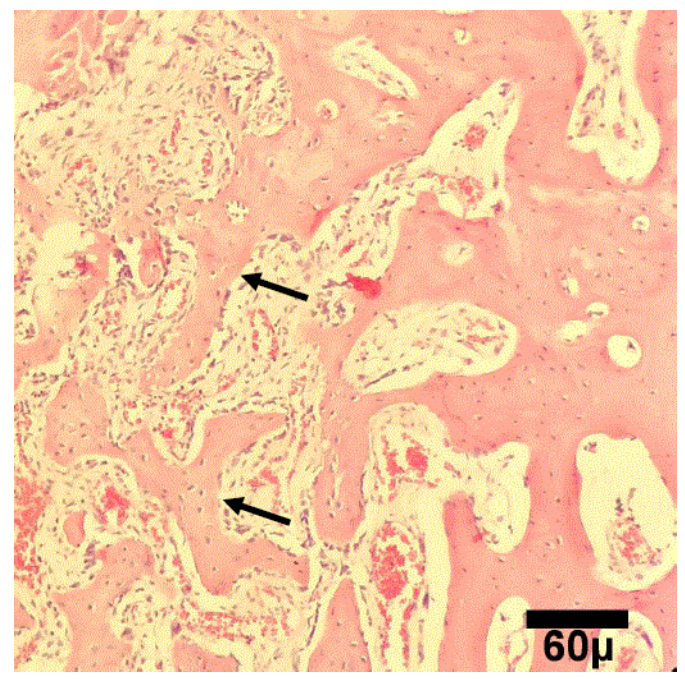

Fig. 10. Microscopic view of healing area in tricalcium phosphate (TCP) group on day 45. Lamellar bone formation (arrows) in healing site is shown $(\mathrm{H} \& \mathrm{E}, 100 \times)$

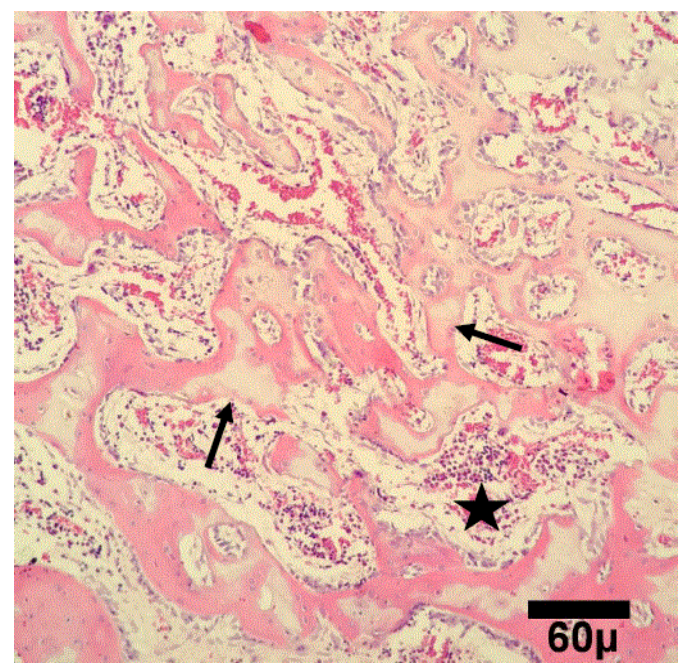

Fig. 11. Microscopic view of healing area in hydroxyapatite group on day 45 . The defect is filled with primary bone (arrows) and well-formed marrow (star) $(\mathrm{H} \& \mathrm{E}, 100 \times)$

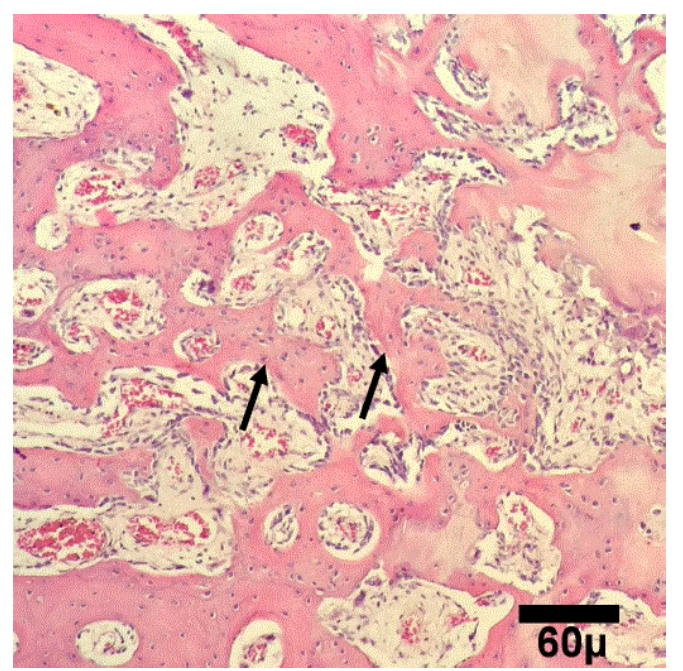

Fig. 12. Microscopic view of healing area in PCL group on day 45. The defect is filled with lamellar (arrows) bone $(\mathrm{H} \& \mathrm{E}, 100 \times)$ 


\section{Discussion}

Although bone has the ability to regenerate itself, some pathological or non-pathological conditions can lead to loss of this inherent ability, a situation which requires the use of bone scaffolds. In cases where the magnitude of the defect is greater than usual, the use of a bone replacement is necessary, in which case bone grafting is the only option available (9). The purpose of this study was to evaluate new bone formation using PCL nanocomposites compared with its formation with the help of TCP and HA in the rabbit femur. It seems that there was evidence of an advanced phase of remodelling and consolidation developing the Haversian system in the PCL group. In addition, the quantity of newly formed lamellar bone was greater than in other groups after 45 days.

This result is consistent with the findings of Esteves et al. (2016) who showed that the bone repair of surgical defects filled with nanocomposite PCL occurred earlier than that of surgical defects filled with TCP or HA. It is likely that such a result is due to the osteoinduction effect of PCL with increased regenerative potential of different growth factors and their cellular activity (14).

There are significant ongoing attempts to design composite materials such as polymers and ceramics, to imitate bone microstructure. TCP and HA have been the subject of most studies because they have structure similar to the inorganic structure of bone and have osteoconductive properties (15).

Mature compact bone is composed of about $70 \%$ inorganic salts and $30 \%$ organic matrix. The main mineral component of bone matrix is HA crystals consisting of calcium and phosphate. HA has good bioactivity and osteoconductivity (16), but is mechanically weak. Calcium phosphate as a bone replacement material is used for bone grafts, and several studies have demonstrated that calcium phosphate has excellent resorbability and osteoconduction when filling the bone defect (21). However, TCP and HA also show fragility, which is a poor match for the mechanical properties of the natural tissue.

PCL is used as raw material in the manufacture of bone scaffolds (11) and is also blended with osteoconductive ceramics such as forsterite (30), calcium alginate (29), HA (4, 7, 22, 28), magnesium phosphate (MP) (19), bioactive glass microspheres (BGMs) (2), and TCP (17, 24). In addition, polypropylene can be mixed with natural polymer to produce bone scaffolds such as silk fibroin (SF) (27). PCL is a multipurpose biodegradable polymer having extraordinary potential in tissue engineering. It is nontoxic in nature and has been found to be cytocompatible with several body tissues, which makes it an ideal material for tissue engineering. Abedalwafa et al. (1) authored a review about applications of the biodegradable poly-epsilon caprolactone. Recent advances in nanotechnology have provided opportunities and facilities in the field of biomedical materials to achieve both excellent biological performance and sufficient mechanical properties. It is well known that nanomaterials have specific properties such as extraordinary strength and toughness which are considerably superior to other conventional materials. Many studies have shown that a PCL scaffold has great effect in bone healing. In the last decade, the utilisation of PCL in tissue engineering had been widely developed. Bae et al. (6) showed the effectiveness of a honeycomb-like polycaprolactone scaffold as a carrier for the bone morphogenetic protein-2 (rhBMP2), which promoted bone healing in a large defect in rabbit ulna. Their study was preclinical evidence that demonstrates the potential of combining of osteoinductive rhBMP2 with PCL constructs for the repair of large bone defects in the clinical realm.

Ciapetti et al. (10) reported that PCL-based polymers have a positive interaction with cells, as they are capable of promoting osteoblast growth and functions. In that study, four different PCL-based polymers were prepared and tested in vitro using osteoblast-like Saos-2 cells. Biochemical cell parameters to evaluate cell/material interactions, including proliferation and viability, alkaline phosphatase secretion, and mineralisation of osteoblastic cells, were selected, and their morphology was examined using light microscopy and SEM. They demonstrated that PCL is a promising material with which to build three-dimensional scaffolds for bone formation and is so also because its similarity to bone structure promotes osteoblast activity.

Eftekhari et al. (13) compared PCL scaffolds with HA scaffolds in repair of rabbit femoral defects. Histopathological evaluation on day 45 showed that the amount of newly formed lamellar bone in the healing site in the nanocomposite PCL group was more abundant than in other treatment groups. In addition, the results indicated that nanocomposite PCL has a main role in the healing of bone defects, and therefore it can be used as a scaffold for bone fracture repair.

In another study by Lee et al. (18) in rabbits, the bone-healing capacity of PCL/poly (lactic-co-glycolic acid) (PLGA)/duck beak scaffold in critical bone defects, and the oxidative stress status of the graft site were evaluated. Micro-CT, X-ray, biochemistry, and histological analyses indicated that the PCL/PLGA/duck beak scaffold enhances new bone formation in rabbit radius, therefore it can be a good choice to accelerate healing of fractures.

Vikingsson et al. (26) evaluated the effect of the implantation of a PCL scaffold with a subchondral bone anchoring pin for tissue repair. In this study, a biodegradable PCL scaffold was placed in a cartilage defect in the femoral condyle of the knee joint of sheep. Histological and mechanical assessment was performed 4.5 months later. The results indicated there was an improvement in this tissue. 
In a study conducted by Di Liddo et al. (12), synthetic HA or rat bone extracellular matrix powder (BP) was used to optimise the mechanical properties

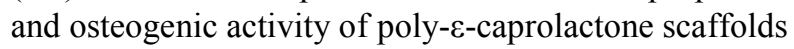
prepared with alginate threads (PCL-AT). Their study showed that PCL-AT scaffolds as the porogen and HA or BP acquired similar osteoinductive properties but were different in their mechanical strength (18).

Rezaei et al. (23) synthesised hydroxyapatite/ polycaprolactone (HA/PCL) nanocomposite by an in situ sol-gel process and studied the chemical and physical properties of the nanocomposite. In this study, PCL was used as a matrix and the nano-hydroxyapatite scaffold was applied as a reinforcement element of the composite. The results indicated that the prepared HA/PCL nano-scaffolds showed good potential for many clinical applications in tissue engineering and could be used for bone grafting and maxillofacial surgery.

In conclusion, the results of this study indicate that nanocomposite PCL has great potential for forming scaffolds to be extensively used for the repair of bone defects. Overall, we believe, with ongoing advances in nanotechnology, nanostructured implant materials will have a bright future in bone repair. nanocomposite PCL has positive effects on the bone healing process, and it can therefore be used as scaffold material in orthopaedic surgery.

Conflict of Interests Statements: The authors declare that there is no conflict of interests regarding the publication of this article.

Financial Disclosure Statement: This study was not funded by any funding agency and was conducted at the expense of the researchers.

Animal Rights Statement: The experiments on animals were conducted in accordance with the Committee of Ethics in Research with animals at the Islamic Azad University (Tehran, Iran).

\section{References}

1. Abedalwafa M., Wang F., Wang L., Li C.: Biodegradable polyepsilon-caprolactone (PCL) for tissue engineering applications: a review. Rev Adv Mater Sci 2013, 34, 123-140.

2. Ahmed I., Parsons A.J., Palmer G., Knowles J.C., Walker G.S., Rudd C.D.: Weight loss, ion release and initial mechanical properties of a binary calcium phosphate glass fibre/PCL composite. Acta Biomater 2008, 4, 1307-1314.

3. Aminzare M., Amir E., Abbasi Z., Hassanzad Azare H., Hashemi M.: Evaluation of in vitro antioxidant characteristics of corn starch bioactive films impregnated with Bunium persicum and Zataria multiflora essential oils. Annual Res Rev Biol 2017, $15,1-9$.

4. Asti A., Gioglio L.: Natural and synthetic biodegradable polymers: different scaffolds for cell expansion and tissue formation. Int J Artif Organs 2014, 37, 187-205.

5. Azi M.L., Aprato A., Santi I., Junior M.J., Masse A., Joeris A.: Autologous bone graft in the treatment of post-traumatic bone defects: a systematic review and meta-analysis. BMC Musculoskeletal Disorders 2016, 17, 465-475.

6. Bae J.H., Song H.R., Kim H.J., Lim H.C., Park J.H., Liu Y., Teoh S.H.: Discontinuous release of bone morphogenetic protein-2 loaded within interconnected pores of honeycomb-like polycaprolactone scaffold promotes bone healing in a large bone defect of rabbit ulna. Tissue Eng 2011, 19, 2389-2397.

7. Bahareh Azimi B., Nourpanah P., Rabiee M., Arbab S.H.: Poly ( $\varepsilon$-caprolactone) Fiber: an overview. J Eng Fibers Fabrics 2014, 9, 74-90.

8. Basu P., Sharan B.S., Kumar U.N., Manjubala I.: Polymer ceramic composite for bone regeneration application. Int $\mathrm{J}$ Chem Tech Res 2014, 16, 4038-4041.

9. Burg K.J.L., Porter S., Kellam J.F.: Biomaterial developments for bone tissue engineering. Biomaterials 2000, 21, 2347-2359.

10. Ciapetti G., Ambrosio L., Savarino L., Granchi D., Cenni E., Baldini N., Pagani S., Guizzardi S., Causa F., Giunti A.: Osteoblast growth and function in porous poly epsilon caprolactone matrices for bone repair: a preliminary study. Biomaterials 2003, 24, 3815-3824.

11. Diba M., Kharaziha M., Fathi M.H., Gholipourmalekabadi M., Samadikuchaksaraei A.: Preparation and characterization of polycaprolactone/forsterite nanocomposite porous scaffolds designed for bone tissue regeneration. Comp Sci Technol 2012, $72,716-723$

12. Di Liddo R., Paganin P., Lora S., Dalzoppo D., Giraudo C., Miotto D., Tasso A., Barbon S., Artico M., Bianchi E., Parnigotto P.P., Conconi M.T., Grandi C.: Poly-\&-caprolactone composite scaffolds for bone repair. Int J Mol Med 2014, 34, $1537-1546$.

13. Eftekhari H., Jahandideh A.R., Asghari A., Akbarzadeh A., Hesaraki S.: Assessment of polycaprolacton (PCL) nanocomposite scaffold compared with hydroxyapatite (HA) on healing of segmental femur bone defect in rabbits. Artif Cells Nanomed Biotechnol 2016, 30, 1-8.

14. Erisken C., Kalyon D.M., Wang H.: Functionally graded electrospun polycaprolactone and beta-tricalcium phosphate nanocomposites for tissue engineering applications. Biomaterials 2008, 29, 4065-4073.

15. Grandi C., Di Liddo R., Paganin P., Lora S., Dalzoppo D., Feltrin G., Giraudo C., Tommasini M., Conconi M.T., Parnigotto P.P.: Porous alginate/poly ( $\varepsilon$-caprolactone) scaffolds: preparation, characterization and in vitro biological activity. Int J Mol Med 2016, 27, 455-467.

16. Hench L.: Bioceramics: from concept to clinic. J Am Ceram Soc 1991, 74, 1487-1510.

17. Komaki H., Tanaka T., Chazono M., Kikuchi T.: Repair of segmental bone defects in rabbit tibiae using a complex of $\beta$-tricalcium phosphate, type I collagen, and fibroblast growth factor-2. Biomaterials 2006, 27, 5118-5126.

18. Lee J.Y., Son S.J., Son J.S., Kang S.S., Choi S.H.: Bone-healing capacity of PCL/PLGA/duck beak scaffold in critical bone defects in a rabbit model. Biomed Res Int 2016, ID 2136215, $1-10$.

19. Lei B., Shin K.H., Noh D.Y., Koh Y.H., Choi W.Y., Kim H.E.: Bioactive glass microspheres as reinforcement for improving the mechanical properties and biological performance of poly ( $\varepsilon$-caprolactone) polymer for bone tissue regeneration. J Biomed Mater Res B Appl Biomater 2012, 100, 967-975.

20. Mohammadi H., Hafezi M., Nezafati N., Hesaraki S., Nadernezhad A., Ghazanfari S.M.H., Sepantafar M.: Bioinorganics in bioactive calcium silicate ceramics for bone tissue repair: bioactivity and biological properties. J Ceram Sci Technol 2014, 5, 1-12.

21. Murphy C., Kolan K., Li W., Semon J., Day D., Leu M.: 3D bioprinting of stem cells and polymer/bioactive glass composite scaffolds for bone tissue engineering. Int J Bioprint 2017, 3, $1-11$.

22. Ogose A., Hotta T., Hatano H., Kawashima H., Tokunaga K., Endo N.: Histological examination of beta-tricalcium phosphate graft in human femur. J Biomed Mater Res 2002, 63, 601-604. 
23. Rezaei A., Mohammadi M.R.: In vitro study of hydroxyapatite/polycaprolactone (HA/PCL) nanocomposite synthesized by an in situ sol-gel process. Mater Sci Eng C Mater Biol Appl 2013, 33, 390-396.

24. Roohani-Esfahani S.I, Lu Z.F., Li J.J., Ellis-Behnke R., Kaplan D.L., Zreiqat H.: Effect of self-assembled nanofibrous silk/polycaprolactone layer on the osteoconductivity and mechanical properties of biphasic calcium phosphate scaffolds. Acta Biomater 2013, 8, 302-312.

25. Verrier S., Alini M., Alsberg E., Buchman S.R., Kelly D., Laschke M.W., Menger M.D., Murphy W.L., Stegemann J.P., Schütz M., Miclau T., Stoddart M.J., Evans C.: Tissue engineering and regenerative approaches to improving the healing of large bone defects. Eur Cells Mat 2016, 32, 87-110.

26. Vikingsson L., Sancho-Tello M., Ruiz-Saurí A., Martínez Díaz S., Gómez-Tejedor J.A., Gallego Ferrer G., Carda C., Monllau J.C., Gómez Ribelles J.L.: Implantation of a polycaprolactone scaffold with subchondral bone anchoring ameliorates nodules formation and other tissue alterations. Int J Artif Organs 2015, 38, 659-666.

27. Woodruff M.A., Hutmacher D.A.: The return of a forgotten polymer-polycaprolactone in the $21^{\text {st }}$ century. Prog Polym Sci 2010, 35, 1217-1256.

28. Wu F., Liu C., O’Neill B., Wei J., Ngothai Y.: Fabrication and properties of porous scaffold of magnesium phosphate/ polycaprolactone biocomposite for bone tissue engineering. Appl Surf Sci 2012, 258, 7589-7595.

29. Yu H., Wooley P., Yang S.Y.: Biocompatibility of poly- $\varepsilon-$ caprolactone hydroxyapatite composite on mouse bone marrowderived osteoblasts and endothelial cells. J Orthop Surg Res $2009,4,5$

30. Živadinović M., Andrić M., Milošević V., ManojlovićStojanoski M., Prokić B., Prokić B., Dimić A., Ćalasan D., Brković B.: Histomorphometric evaluation of bone regeneration using autogenous bone and beta-tricalcium phosphate in diabetic rabbits. Vojnosanit Pregl 2016, 73, 1132-1138. 